\title{
Beleza e conflito: a espiritualidade existencial na poesia de Florbela Espanca em diálogo com o livro do Eclesiastes
}

\section{Beauty and conflict: the existential spirituality in the poetry of Florbela Espanca in dialogue with the book of Ecclesiastes}

\section{Belleza y conflicto: la espiritualidad existencial en la poesía de Florbela Espanca en diálogo con el libro del Eclesiastés}

\author{
Antonio Carlos Soares Santos*
}

\begin{abstract}
RESUMO
A poesia de Florbela Espanca é a essência literária da própria existência humana. Há o conflito entre as expressões de religiosidade e as dúvidas e rejeição do mundo religioso. Florbela Espanca expressa na beleza de suas poesias os conflitos originários de uma alma carregada pela angústia, tristeza e dor. Ao lermos Espanca, temos a sensação de adentrarmos no interior da sentimentalidade humana e enxergarmos os cantos obscuros do ser que poucas vezes é exposta. Sem se entregar a um discurso puramente teológico, Espanca vagueia em meios às palavras de cunho religioso e revela a face de um existencialismo que aflora dentro de uma perspectiva quase confessional de alguém que ama a vida, mas que constantemente flertava com a morte. Este trabalho monográfico tenta traçar um diálogo entre a poesia de Florbela Espanca e as nuances do pensamento de uma espiritualidade existencialista.

Palavras chaves: Existencialismo; teologia; poesia.
\end{abstract}

\begin{abstract}
The poetry of Florbela Espanca is the literary essence of human existence itself. There is the conflict between the expressions of religiosity and the doubts and rejection of the religious world. Florbela Espanca expresses in the beauty of her poetry the conflicts originating from a soul charged by anguish, sadness and pain. When we read Espanca we have the sensation of entering human sentimentality and seeing the dark corners of the being that is rarely exposed. Without indulging in a purely theological discourse, Espana wanders in words with religious words and reveals the face of an existentialism that comes from an almost confessional perspective of someone who loves life but who constantly flirts with death. This monographic work tries to draw a dialogue between the poetry of Florbela Espanca and the nuances of the thought of an existentialist spirituality.

Keywords: Existentialism; theology; poetry.
\end{abstract}

* Professor-tutor da Escola de Teologia da Universidade Metodista de São Paulo (Umesp), doutorando em Ciências da Religião. E-mail: antonio.santos@metodista.br 


\section{RESUMEN}

La poesía de Florbela Espanca es la esencia literaria de la propia existencia humana. Hay el conflicto entre las expresiones de religiosidad y las dudas y el rechazo del mundo religioso. Florbela Espanca expresa en la belleza de sus poesías los conflictos originarios de un alma cargada por la angustia, la tristeza y el dolor. Al leer a la española, tenemos la sensación de adentrarnos en el interior de la sensibilidad humana y ver las esquinas oscuras del ser que pocas veces es expuesta. Sin entregarse a un discurso puramente teológico, Espanca vaga en medios a las palabras de cuño religioso y revela la cara de un existencialismo que aflora dentro de una perspectiva casi confesional de alguien que ama la vida, pero que constantemente flestaba con la muerte. Este trabajo monográfico intenta trazar un diálogo entre la poesía de Florbela Espanca y los matices del pensamiento de una espiritualidad existencialista.

Palabras claves: Existencialismo; teología; poesía.

\section{Introdução}

A questão do existencialismo no campo da espiritualidade é um caminho progressivamente trilhado. A espiritualidade é um mover constante, muitas vezes permeada por outras abstrações subjetivas como a moralidade e a cultura. Vejamos a espiritualidade como um movimento interior que nasce da necessidade de transcender a realidade concreta e alcançar explicações, conforto ou consolo para o que essencialmente conflita com a própria existência. Essa busca constante refletirá em atitudes e ações. Por isso, podemos considerar que há espiritualidades expressas de formas variadas, pois a expressão dependerá da situação e do desenvolvimento dessa busca. Uma espiritualidade existencialista é aquela em que as respostas não existem, assim como as certezas, características de uma crença fomentada por uma fé inquestionável. A face existencialista de uma espiritualidade encontra guarida nas próprias dúvidas e sentimentos que por elas são alimentadas. Amor, dor, solidão, medo, paixão, tristeza ou/e alegria, são expressões de humanidade abordada pelas religiões, algumas mais, outras menos, e geralmente encontram argumentações favoráveis e suficientes em seus próprios textos sagrados. No entanto, nada é mais existencialmente humano do que a poesia e nada mais existencial dentro da Bíblia do que o livro do Eclesiastes.

A poesia como elemento de sentimentalidades escritas, transporta com sucesso as angústias e anseios do ser humano para leitores e/ou ouvintes. Em se tratando de uma espiritualidade existencialista, a poesia transporta mais que emoções, também os olhares a respeito da relação com o sagrado e de como essa relação pode influir na vida e na morte. Florbela Espanca soube como ninguém expressar humanidade e divindade por meio de seus próprios conflitos e assim, abordar o que há de mais intenso no sentimento e existência humana. Espanca é a expressão sombria e perturbadora de uma espiritualidade que ama a vida, mas flerta constantemente com a morte, fruto de um eterno anseio inalcançável, como ela mesma diz no poema "O meu impossível": 
Tudo é vago e incompleto! E o que mais pesa

É nada ser perfeito. É deslumbrar

A noite tormentosa até cegar,

E tudo ser em vão! Deus, que tristeza!...

\section{Sobre Florbela Espanca e Eclesiastes}

Florbela Espanca, poetisa portuguesa, nasceu em 8 de dezembro de 1894, em cujo registro civil consta como seu nome Flor Bela Lobo. Florbela viveu durante trinta e seis anos, teve uma vida tumultuada e cheia de sofrimentos, que eram transformados em poesias, cheias de erotização e feminilidade. Tentou suicidar-se por duas vezes, em outubro e novembro de 1930, às vésperas da publicação de sua obra-prima. Após o diagnóstico de um edema pulmonar, suicidou-se no dia do seu aniversário.

Florbela é egocêntrica, sua poesia gira em torno de si mesma e de seu mundo, por vezes pequeno. Não se preocupa com política e nem questões sociais. O que se percebe é uma intensidade da sentimentalidade que vai além de seu tempo em se tratando de escritos femininos. A morte do irmão em um acidente aéreo e uma paixão malsucedida, vão influenciar em muito a obra de Florbela. É de opinião quase unânime que Florbela Espanca não se ligou totalmente a qualquer movimento literário. Está mais perto do simbolismo ${ }^{1} \mathrm{e}$ de certos poetas do fim do século XIX. Pelo caráter confessional, sentimental, da sua poesia, segue a linha de Antonio Nobre ${ }^{2}$, fato reconhecido pela poetisa. Por outro lado, a técnica do soneto, que a celebrizou, é, sobretudo, influência de Antero de Quental.

Eclesiastes é um livro único dentro da conhecida literatura canônica hebraica. Não se sabe quem é o autor que se identifica como "Qohelet". Não há qualquer menção clara sobre o período em que foi escrito. Storniolo e Balancin acreditam que todos os indícios levam a crer que o autor escreveu em meados do século III a.C., provavelmente por volta do ano 250 a.C. Afirmam, ainda, que o livro "reflete a situação histórica e as condições sociais em que vivia o seu povo na Palestina" (STORNIOLO; BALANCIN, 1990, p. 8).

$\mathrm{O}(\mathrm{s})$ autor(es) escreve sobre seus sucessos e suas frustrações e sobre todas as maneiras pelas quais tentou ter sucesso e fazer qualquer coisa de sua vida e ainda sobre todas as razões por que nunca conseguiu responder realmente a pergunta: Qual o significado de tudo isso, a longo prazo? Do Eclesiastes se

\footnotetext{
1 Os autores voltam-se à realidade subjetiva, às manifestações metafísicas e espirituais, abandonadas desde o Romantismo. Buscava a essência do ser humano, a alma; a oposição entre matéria e espírito, a purificação do espírito, a valorização do inconsciente e do subconsciente.

2 António Nobre (1867-1900) foi um poeta português, criou sua própria forma de escrita, aliando a subjetividade do Romântico ao poder de sugestão do Simbolismo.
} 
tem dito que é o livro mais pessoal da Bíblia. Os profetas e outros autores bíblicos fazem relatos sobre suas dificuldades e adversidades, suas conquistas e experiências. No entanto, em nenhum outro escrito do Primeiro Testamento encontramos uma confissão tão pessoal quanto a encontrada nas páginas de Eclesiastes, com seus mais profundos temores e frustrações.

\section{A poesia, a espiritualidade e o existencialismo: morte e vida em questão}

Espiritualidade(s) é a busca de nomeação aos misteriosos e diferentes caminhos do ser humano a Deus, segundo Barcellos (2001, p. 17). Então, entendemos a espiritualidade como um estado dinâmico da alma, sempre em constante movimento. Como enunciado anteriormente, é a necessidade de transcender o visível e o previsível. A alma humana inquieta externa os conflitos dessa busca e, porque não dizer, perdições. Existir é conflitante. Nesse ponto, Florbela nos traz a memória o texto sapiencial da Bíblia judaica e cristã, Eclesiastes, onde a vida e a espiritualidade entram em conflito com a realidade. Viver em busca das compreensões de uma interioridade em certos aspectos incompreensível faz com que o entendimento da realidade não seja suficiente para encontrar o que seja satisfatório para responder as dúvidas inquietantes que impulsiona a essa mesma busca.

O texto poético traz a capacidade de transpor o utópico sentimento que sobrepuja a realidade concretizada. Em se tratando da poesia de Florbela Espanca, o eu poético florbeliano tem a capacidade de se metamorfosear e jogar com as formas do mundo e da vida, o que confere à sua poesia uma sedução própria da alteridade. Nesse caso, a devotada abordagem no diálogo entre a vida sem sentido e a morte, são temas constantes em seus poemas que demonstram conflitos existenciais e que são acompanhados por uma concepção intimista de Deus, em uma dança de pensamentos e sentimentos que são permeados por uma feminilidade erótica-religiosa. Maria Lúcia Dal Farra, no prefácio à obra de Florbela, destacou que:

A escolha do sonho como registro de capturação da realidade, o peso concreto da morte, associado ao amor, e a escolha de valores noturnos enquanto específicos designadores do feminino. E, desde aqui, desde a nascente da poética de Florbela, ficam definitivamente seladas e imbricadas as suas mais significativas constantes: a condição feminina e a marginalidade. Tanto o sonho, quanto a morte abrem a vida, para esta jovem poetisa, em um espaço intervalar revertem-na num universo de exceção, num mundo fora-da-existência que, gratificantemente, abre uma brecha na ordem inabalável e convencional. Aí, a vida se desloca do curso habitual e as regras se tornam outras. Há uma suspensão do tempo real e do espaço físico, que contraria o principio da realidade, visto por Florbela como prerrogativa masculina, e que instaura, ao contrário, o princípio do prazer, atribuição feminina (FARRA, 1996, p. 17). 
Deus, na poesia de Florbela Espanca não é o absoluto, mas vagueia no conceito panteísta cristão, imanente e transcendente: "Deus se manifesta em tudo" e assim, passa a ser agente em uma dinâmica eu-divino sem que com isso haja uma relação doutrinária. Para analisarmos a espiritualidade e existencialismo no poema de Florbela Espanca destacaremos dois poemas que podem nos auxiliar na compreensão do pensamento florbeliano. Florbela Espanca revela primeiramente para si e, posteriormente, para seus leitores, uma forma de expressão poética que constituirá a sua identidade literária mais marcante: o valor do panteísmo, a utilização da natureza enquanto metáfora do corpo e da sensualidade. A subversidade nos poemas de Espanca se encontra na própria ousadia de mostrar os sentimentos aflorados e intensos, marcados por um discurso erótico sem perder a relação sacralizada de seu mundo pessoal. Discurso esse, que se encontra conectado à vida, paixão e morte.

O poema que analisaremos leva-nos a uma visão profunda do pensamento e sentimentos em Florbela Espanca:

A um Moribundo

Não tenhas medo, não! Tranquilamente,

Como adormece a noite pelo Outono,

Fecha os teus olhos, simples, docemente,

Como, à tarde, uma pomba que tem sono...

A cabeça reclina levemente

E os braços deixa-os ir ao abandono,

Como tombam, arfando, ao sol poente,

As asas de uma pomba que tem sono...

O que há depois? Depois?... O azul dos céus?

Um outro mundo? O eterno nada? Deus?

Um abismo? Um castigo? Uma guarida?

Que importa? Que te importa, ó moribundo?

- Seja o que for, será melhor que o mundo!

Tudo será melhor do que esta vida!...

O simbolismo da escuridão, melancolia, vida sem sentido, a alma ferida, são traços marcantes e regulares nas poesias de Florbela Espanca. O existencialismo é abrigado em um discurso alimentado por abordagens do sagrado. Espanca cai em um existencialismo onde a grande angústia é vista de forma individualista, em seu mundo particular e pessoal, fugindo de uma visão generalizada com a sociedade.

Fecha os teus olhos, simples, docemente,

Como, à tarde, uma pomba que tem sono... 
Esse mundo mergulhado em escuridão (fechar os olhos) é frequente. A ausência de luz traz à tona sua própria descrença, não em Deus, mas em sua própria fé e concepção de sagrado. O sentido de vida ou a falta dele é frequentemente condicionado a momentos que parecem ser desejados eternamente.

A cabeça reclina levemente

E os braços deixa-os ir ao abandono.

Qual seria, portanto, o objeto de devoção de espanca? Analisando o texto percebemos que a solidão é a realidade a qual se apresenta a ela e a qual se entrega. Solidão que a leva ao desejo da morte. Temos assim, um pessimismo em relação, sobretudo, ao seu futuro. Há um distanciamento em relação ao existencialismo cristão e uma forte aproximação ao existencialismo filosófico-ateu:

...a análise filosófica, como tem mostrado Heidegger, só pode explicar que o homem deve estar aberto ao futuro, se quer existir em um sentido plenamente pessoal. Também pode chamar a atenção sobre o efeito, estimulante ou deprimente, que o homem experimenta ante a afirmação de que, para a análise filosófica, o futuro só pode ser definido como o nada (BULTMANN, 2003, p. 61).

Diferentemente, Eclesiastes aborda a morte, mas não a vê de uma maneira amigável. Lamenta sua chegada e nos leva ao entendimento de que a vida, ainda que carregada pela rudeza é melhor do que a suposta suavidade da morte. E se a morte é o fim de todos "mais vale um cão vivo que um leão morto", afirma o autor de Eclesiastes 9.4. Além de ter muito menos força que um leão, o cão, no Oriente Primeiro, era considerado um animal impuro e, por isso, sem valor na sociedade. Já o leão representava a realeza. Aqui, diante da fatalidade da morte, é melhor ser fraco, pobre e desprezado, mas estar vivo, que rei, mas morto. O dinheiro e a luxuria não compram a vida. É melhor ser pobre vivo que rei morto. Portanto, não importando as dificuldades e decepções, ao contrário das palavras de Florbela Espanca, Eclesiastes celebra a vida, mas não nega a sina da humanidade na morte. No entanto, a constatação da morte deve levar o ser humano a viver com intensidade a vida, procurando sempre a sua felicidade. Olhando para o presente.

No poema de Florbela Espanca, a realidade futura única e possível era justamente o nada. O sentido de vida nas poesias de Florbela Espanca, desemboca em uma constante espera pela morte. O que se percebe é que em seus escritos, os desmandos e decepções a levam a uma visão de que a vida é vazia. Como o (a) autor (a) do livro de Eclesiastes, a constatação 
e de que a morte é iminente, já que a vida não traz qualquer sentido. Sua espiritualidade reconhece a existência do sagrado, mas essa existência não se aplica a sua própria vivência. Neste ponto, novamente a poesia se difere do texto de Eclesiastes.

Enquanto o Eclesiastes parte de uma perspectiva um tanto negativista quanto à dinâmica da vida, entretanto, caminhando para um consolo divino ao final de tudo, em Florbela há uma imagem de um deus distante e inerte que contempla seu sofrimento sem, no entanto, intervir a seu favor. $\mathrm{Na}$ verdade, a ideia que se tem dentro da perspectiva florbeliana é que seu sofrimento é uma forma de penitência que se carrega em si mesmo. Novamente percebe-se a presença da solidão em face com a morte como parte inerente de sua experiência de vida. O sentido de vida é corrompido em favor de um diálogo visível com a falta de esperança. Eclesiastes faz algo semelhante ao demonstrar a realidade de uma existência vazia, e assim, a poesia de Florbela Espanca, de uma forma intimista, compartilhar com o texto de Eclesiastes da visão crua e bruta da vida que a cerca:

A cabeça reclina levemente

E os braços deixa-os ir ao abandono,

Como tombam, arfando, ao sol poente,

As asas de uma pomba que tem sono...

Melhor é a boa fama do que o melhor unguento, e o dia da morte, do que o dia do nascimento de alguém.

Melhor é ir à casa onde há luto do que ir à casa onde há banquete, porque ali se vê o fim de todos os homens; e os vivos o aplicam ao seu coração.

Melhor é a tristeza do que o riso, porque com a tristeza do rosto se faz melhor o coração (Eclesiastes $7.1-3) .^{3}$

A morte é o ponto final e a solução de uma vida sem sentido ${ }^{4}$ no poema de Florbela Espanca. Florbela não vê a vida sem sentido em razão de uma inevitável chegada da morte, mas vê a morte como solução para uma vida sem sentido. Em seu poema "A um moribundo", Espanca abraça a morte como consolo e aconchego:

Não tenhas medo, não! Tranquilamente,

Como adormece a noite pelo Outono,

Fecha os teus olhos, simples, docemente,

Como, à tarde, uma pomba que tem sono... (A um Moribundo).

BÍBLIA SAGRADA, 1998. Todos os textos bíblicos citados neste artigo são dessa edição.

4 Vale ressaltar que esse tema e linha de pensamento permeiam quase todos os poemas de Florbela Espanca. É uma característica marcante em seus escritos. 
De forma semelhante, Eclesiastes aborda o tema, sem, no entanto, cair em uma afirmação de morte como solução de uma vida compreendida como sem sentido. Enquanto Florbela se entrega e deseja a realidade da morte, Eclesiastes adverte que é o caminho natural, sem com isso exaltá-la:

Porque o que sucede aos filhos dos homens, isso mesmo também sucede aos animais; a mesma coisa thes sucede: como morre um, assim morre o outro, todos têm o mesmo fôlego; e a vantagem dos homens sobre os animais não é nenbuma, porque todos são vaidade. Todos vão para um lugar; todos são pó e todos ao pó tornarão (Eclesiastes 3.19-20).

A cabeça reclina levemente

E os braços deixa-os ir ao abandono,

Como tombam, arfando, ao sol poente,

As asas de uma pomba que tem sono...

O que há depois? Depois?... O azul dos céus?

Um outro mundo? O eterno nada? Deus?

Um abismo? Um castigo? Uma guarida? (A um moribundo).

Percebe-se que, apesar das diferenças de perspectiva em relação à temática da morte e a vida sem sentido, há um elo quanto à suas existências encadeadas. A afirmação de que a vida é sem sentido porque termina em morte relaciona-se com a afirmação de que tudo o que tem sentido precisa durar para sempre. Não é o que parece compartilhar os poemas de Florbela Espanca, e nem o que nos faz entender o texto de Eclesiastes. Porém, eternidade não é certeza de sentido de vida. Para ilustrar a ideia de que sentido de vida e eternidade não é necessariamente uma construção de realização, recordamos o mito de Sísifo. Na mitologia grega Sísifo é punido pelos deuses por tê-los enganados. Sua punição é ser forçado a rolar uma enorme pedra até o topo de uma montanha. Assim que a pedra chega ao topo, ela é rolada novamente até a base da montanha. Sísifo está condenado a repetir esta tarefa inútil por toda a eternidade. No mito de Sísifo, encontramos a existência alicerçada no vazio. E a grande punição é uma vida eterna mergulhada em uma existência sem sentido.

A duração da vida nada tem a ver com ela ter ou não sentido. A morte é um elemento chave na interpretação do livro de Eclesiastes. Para refletir acerca da vida e o sentido que ela carrega, o autor fala da morte. A constatação da existência da morte, faz compreender a riqueza e preciosidade de estar vivo, aponta o autor de Eclesiastes. Tudo que não leva a vida a ser vivida intensamente é "vaidade das vaidades", "vazio dos vazios". É a morte que dá sentido e desejo pela vida. A partir da morte se descobre a importância de viver. Em Florbela Espanca, a poetisa oferece o caminho da morte como saída para uma vida sofrida. 
Ao lermos os poemas de Florbela, entendemos que o grande e incomodo da poetisa é não encontrar mais perspectivas para uma vida. $\mathrm{O}$ vazio existencial se consume na ideia de que tudo se torna inútil e que, portanto, a sua realização de vida está na morte:

\section{Que importa? Que te importa, ó moribundo? \\ - Seja o que for, será melhor que o mundo! \\ Tudo será melhor do que esta vida!... (A um Moribundo).}

A vida para Espanca é um suplício e um castigo considerável. Em Eclesiastes encontramos não talvez a realização de uma vida sem sentido na morte, mas nos deparamos com a ideia de que a morte é o final de todos e que realmente em muitos aspectos, a vida não toma sentido algum:

\footnotetext{
Pelo que eu disse no meu coração: Como acontece ao tolo, assim me sucederá a mim; por que, então, busquei eu mais a sabedoria? Então, disse no meu coração que também isso era vaidade.

Porque nunca haverá mais lembrança do sábio do que do tolo; porquanto de tudo nos dias futuros total esquecimento haverá. E como morre o sábio, assim morre o tolo!

Pelo que aborreci esta vida, porque a obra que se faz debaixo do sol me era penosa; sim, tudo é vaidade e aflição de espírito (Eclesiastes 2.15-17).
}

Mas ainda assim, Eclesiastes vê o presente como meio de felicidade, enquanto Espanca enxerga o presente como uma razão para se entregar à morte.

\section{Considerações finais}

Florbela Espanca é a síntese de uma interioridade conflitante e solitária. Seu existencialismo e sua relação com sagrado estão sempre contornados com o pensamento obsessivo de que a morte é o grande descanso. A semelhança com o texto de Eclesiastes está na certeza de que a morte é iminente e inevitável. A diferença está em que os poemas de Espanca dão as boas-vindas a morte, porque enxerga nela o alívio, enquanto Eclesiastes vê a morte como destino irrefutável e consequência natural da vida, da maneira que vier. Florbela Espanca declara: Seja o que for, será melhor que o mundo! Tudo será melhor do que esta vida!... (A um Moribundo). Já Eclesiastes afirma: Todos vão para um lugar; todos são pó e todos ao pó tornarão. Morte e vida são para ambos os textos a dicotomia fundamental da existência humana, porém, para Florbela Espanca é mais que isso, é a morte a realização e a fuga da vida sem sentido e não sua consequência. 


\section{Referências bibliográficas}

BARCELLOS, José Carlos. Literatura e Espiritualidade: uma leitura de Jeunes Années, de Julien Green. Bauru, SP: Editora da USC, 2001.

BÍBLIA SAGRADA. Edição rev. e corrigida da trad. de João Ferreira de Almeida. Barueri, SP: SBB, 1998.

BULTMANN, Rudolf. Jesus Cristo e Mitologia. São Paulo: Novo Século, 2003.

DAL FARRA, Maria Lúcia. Poemas de Florbela Espanca. Estudo introdutório, organização e notas de Maria Lúcia Dal Farra. São Paulo: Martins Fontes, 1996.

STORNIOLO, Ivo; BALANCIN, Euclides Martins. Como Ler o Livro do Eclesiastes: trabalho e felicidade. São Paulo: Paulinas, 1990.

Submetido em: 5-6-2019

Aceito em: 11-6-2019 